\title{
Case Report on Two Large Duodenal Perforations and Their Management in Emergency Conditions
}

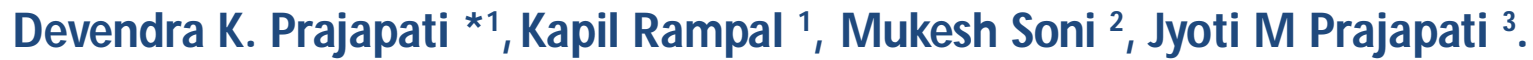

${ }^{* 1}$ Senior Resident Department of Surgery, Deendayal Upadhyay Hospital, New Delhi, India.

*2 DNB (sch) Department of Surgery, Deendayal Upadhyay Hospital, New Delhi, India.

*3 Scholar in Computer Application, Deendayal Upadhyay Hospital, New Delhi, India.

\section{ABSTRACT}

Duodenal trauma and its management has always been a hard task and presents as a situational dilemma in surgical emergencies. Very limited work guidelines and standards are available for the management of these complex injuries. Triple tube technique as pure procedure or with its situational modifications is seen as an ideal repair for duodenal perforations. Gastrojejunostomy seemingly is a better option to gastrostomy when large perforations are being repaired for which lumen narrowing is expected.

KEY WORDS: Duodenum, Trauma, Surgical Emergencies, Triple Tube Technique.

Address for correspondence: Dr. Devendra K Prajapati, WZ 423 A Nanakpura Harinagar, New Delhi, 110064, India. E-M ail: dr.dev1982@gmail.com

\begin{tabular}{|c|c|}
\hline \multicolumn{2}{|r|}{ Online Access and Article Informtaion } \\
\hline \multirow{2}{*}{$\begin{array}{c}\text { Quick Response code } \\
\text { DOI: } 10.16965 / \text { ijims.2016.117 }\end{array}$} & $\begin{array}{c}\text { International Journal of Integrative Medical Sciences } \\
\text { Www.imedsciences.com }\end{array}$ \\
\hline & $\begin{array}{l}\text { Received: 21-04-2016 } \\
\text { Reviewed: 22-04-2016 }\end{array} \begin{array}{l}\text { Accepted: 23-05-2016 } \\
\text { Published: 31-05-2016 }\end{array}$ \\
\hline Source of Funding: Self & Conflicts of interest: None \\
\hline
\end{tabular}

\section{BACKGROUND}

Duodenal traumas are rare cases, but the incidence of these is on an increase with the increase in the number of motor vehicles [1]. Its diagnosis is also difficult because of its anatomical location. The incidence of duodenal injuries as estimated varies from 3\% to $5 \%$. M ost duodenal injuries, estimated to be around 75\% are caused by penetrating trauma while, rest $25 \%$ injuries are due to blunt injury or a direct blow to the epigastrium. Blunt trauma injuries are rare, and difficult to diagnose because patients may have suboptimal signs when first time attending emergencies. M ost of duodenal injuries are associated with intra-abdominal solid organ injuries because of its close anatomical relation to solid organs like liver and kidney [2-4].
The diagnosis of duodenal injury is difficult while it is highly suspected. The presence of highly suspicious clinical history and findings like steering wheel or seat belt injury over the anterior abdominal wall may make the clinician more conscious towards duodenal injury. The physical examination can be misleading because of its retroperitoneal location. Duodenal perforations usually show subtle clinical presentation because of its retroperitoneal location. Tachycardia, right upper quadrant tenderness, vomiting, and a progressive rise in temperature and heart rate are common findings. Intraperitoneal perforations will manifest with typical signs of peritonitis. Retroperitoneal perforations may take several hours or days to produce signs of peritonitis, till duodenal contents spill over into the peritoneal 
cavity. Delay in diagnosis and management definitely contributes to increase the morbidity and mortality [5].

\section{CASE REPORT:}

A 15 years old male patient attended emergency surgery ward with one day history of blunt injury over the abdomen in the right upper quadrant by bicycle handle while cycling. He complains of severe and constant pain in abdomen with vomiting and obstipation since the time of incidence.

On examination: Patient was conscious oriented but drowsy. Have a pulse rate of 110/minute and a systolic blood pressure of $80 \mathrm{~mm}$ of $\mathrm{Hg}$. He was afebrile, but tachypnoeic and dehydrated.

Respiration: Bilateral air entry present, but mild decrease in the right lower zone.

Per abdomen- generalized tenderness, guarding, rebound tenderness present, BS +ve.

DRE- rectum collapsed and empty Rest system WNL

The patient was admitted and immediate IV fluid resuscitation done. When vitals stabilized, all routine and necessary investigations performed. [Table 1]

Table 1: Showing the routine and necessary investigations.

\begin{tabular}{|c|c|}
\hline Investigation & Value \\
\hline Hb & $14.5 \mathrm{gm}$ \\
\hline TLC & $2440 \mathrm{~mm} 3$ \\
\hline platelets & $220000 \mathrm{~mm} 3$ \\
\hline Blood urea & $56 \mathrm{mg} / \mathrm{dl}$ \\
\hline Serum creatinine & $0.9 \mathrm{mg} / \mathrm{dl}$ \\
\hline Serum amylase & $325 \mathrm{IU} / \mathrm{L}$ \\
\hline Serum lipase & $180 \mathrm{IU} / \mathrm{L}$ \\
\hline Nat & 130 meq/l \\
\hline K+ & 4.1 meq/l \\
\hline Chest Xray (PA view) supine & No free gas under the diaphragm \\
\hline USG Whole abdomen & $\begin{array}{c}\text { Small amount of perihepatic } \\
\text { collection with mild free fluid in } \\
\text { peritoneal cavity. No solid organ } \\
\text { iniurv }\end{array}$ \\
\hline CECT whole abdomen & $\begin{array}{c}\text { Mild free fluid in perihepatic, sub } \\
\text { diaphragmatic and pelvis likely } \\
\text { in sub diaphragmatic region s/o of } \\
\text { pneumoperitoneum. M inimal to mild } \\
\text { right pleural effusion. }\end{array}$ \\
\hline
\end{tabular}

Int J Intg M ed Sci 2016;3(5):280-84. ISSN 2394 - 4137
On the basis of clinical examination and radiological investigations, patient planned for exploratory laparotomy.

After proper preoperative preparation and midline laparotomy performed under general anaesthesia. Following intraoperative findings were noted:

\section{Approx. $1000 \mathrm{ml}$ bilious ascites.}

2. There were two large duodenal perforation in second part of duodenum, one over the anterior wall measuring $4 \mathrm{~cm} \times 3 \mathrm{~cm}$ and the other over posterior wall measuring $3 \mathrm{~cm} \mathrm{X} 3 \mathrm{~cm}$, with mucosa pouting out. [Figure 1 and 2]

3. No solid organ trauma.

4. Retroperitoneum normal.

Fig. 1: Arrow showing anterior wall perforation (repaired).

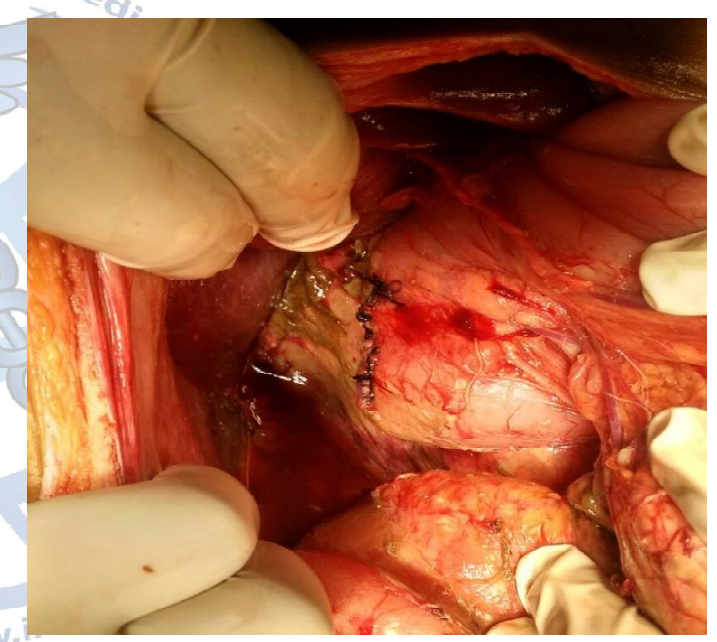

After careful mobilization of duodenum following procedures were performed

1. Primary repair of both duodenal perforations in two layers by 3-0 RB Vicryl and silk.

Fig. 2: Arrow showing posterior wall perforation (repaired).

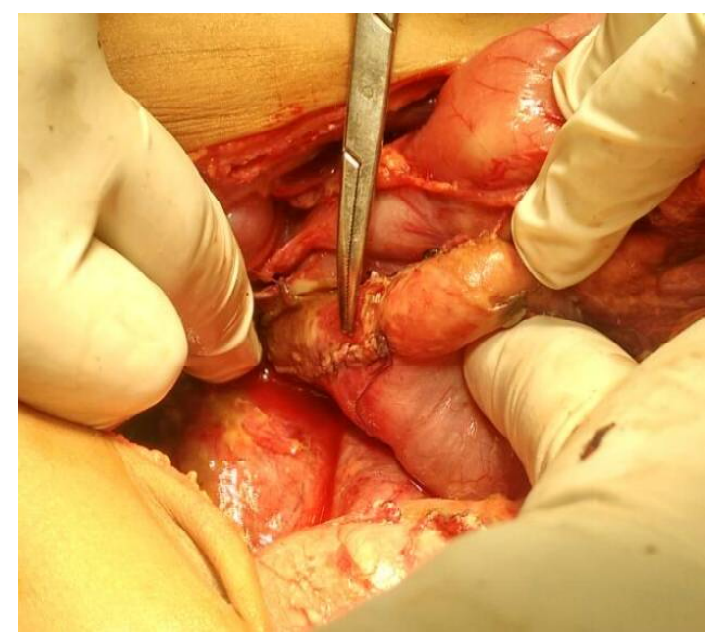


2. Triple tube decompression:

(A) A 14F Ryle's tube progresses retrogradely up to second part of duodenum from antimesentric surface of jejunum, $20 \mathrm{~cm}$ distal to the DJ flexure (retrograde duodenostomy)

(B) Posterior wall, retro colic, isoperistaltic gastrojejunostomy in place of gastrostomy, 30 $\mathrm{cm}$ distal to the DJ flexure.

(C) Ante grade feeding jejunostomy, $45 \mathrm{~cm}$ distal to the DJ flexure using 18F Ryle's tube.

(D) 18 Fr Nasogastric Ryle's positioned.

(E) Drain placed in sub hepatic and pelvis region. Abdomen closed in layers and patient shifted to ICU for postoperative care. Patient developed fever with leukocytosis of 23000 , on the second post-operative day. The antibiotics were upgraded on the basis of subhepatic drain fluid culture. The fever subsided and blood counts normalized.

Jejunostomy feed started on day five but was withheld as the right sub hepatic drain output turned bilious the next day. The patient was started on total parenteral nutrition and the drain output that always was less than $100 \mathrm{ml} /$ day, became nil by 12 th post-operative day. The Ryle's tube was removed on day 15 , duodenostomy with abdominal drains on day 20 and finally feeding jejunostomy removed on day 22 when the patient was able to take a sufficient amount of food by mouth.

Oral gastrograffin contrast study showed free flow of contrast through pylorus into duodenum and a patent gastojejunostomy. Patient was discharged on $30^{\text {th }}$ post-operative day.

\section{DISCUSSION}

It is inferred from the available clinical data on trauma that the pancreas and the duodenum are protected and rarely injured, but whenever they are, the injuries are far more serious and result in higher mortality and morbidity and the diagnosis is invariably delayed. There is very limited evidence based work available and so less available are the standards for the management of these complex injuries. The usual sites for duodenal injury are the second part (36\%), the third part (18\%) and the fourth part (15\%). The least injured part is first part [6].

Int J Intg M ed Sci 2016;3(5):280-84. ISSN 2394 - 4137
Diagnosis of duodenal injury is difficult routinely because the signs and symptoms get masked by injured adjacent organs. A small leak takes many hours to develop a significant collection and produce signs of peritonitis. Common symptoms are high grade fever, generalised abdominal pain and sepsis $[3,4,7,8]$.

Routine blood investigations provide very little help in the early diagnosis of duodenal injuries. The serum level of amylase is considered as an indicator of duodenal injury, but has low sensitivity and specificity [6]. However the serum amylase level can be used as predictive value in admitted patients for observation.

Lucas and Ledgerwood [5] advocated that the serum amylase level monitored every $6-h$. And persistently elevated amylase level may be significance in detecting duodenal injury.

Radiographic studies such as positive plain abdominal x-ray are helpful in diagnosis. On USG abnormal findings like unexplained fluid collections surrounding the duodenum and retroperitoneal free air around the upper pole of right kidney suggest duodenal injury. But often ultrasound has limited access to in the pancreaticoduodenal area.

Table 2: AAST classification for duodenal injury

\begin{tabular}{|c|c|c|}
\hline Grade & 8 & Injury description \\
\hline medds & $\begin{array}{l}\text { Haematoma } \\
\text { Laceration }\end{array}$ & $\begin{array}{l}\text { Involving single portion of duodenum } \\
\text { Partial thickness, no perforation }\end{array}$ \\
\hline$\|$ & $\begin{array}{l}\text { Haematoma } \\
\text { Laceration }\end{array}$ & $\begin{array}{l}\text { Involving more than one portion } \\
\text { Disruption }<50 \% \text { of circumference }\end{array}$ \\
\hline |II & Laceration & $\begin{array}{l}\text { 1.Disruption of } 50-75 \% \text { of circumference } \\
\text { of D2 2. Disruption of } 50-100 \% \text { of } \\
\text { circumference of D1, D3 and D4 }\end{array}$ \\
\hline IV & Laceration & $\begin{array}{l}\text { 1. Disruption of }>75 \% \text { of circumference } \\
\text { of D2 2.Involving ampulla or common } \\
\text { bile duct }\end{array}$ \\
\hline V & $\begin{array}{l}\text { Laceration } \\
\text { Vascular }\end{array}$ & $\begin{array}{l}\text { 1.Massive disruption of pancreatico- } \\
\text { duodenal complex } \\
\text { 2. Devascularisation of the duodenum }\end{array}$ \\
\hline
\end{tabular}

The most useful investigation for diagnosis of duodenal trauma is a CT scan. In CT scan significant findings are retroperitoneal fluid and air collection and severe extent of injury to the adjoining structures. CT scan with both oral and intravenous contrast may detect the extravasation of contrast medium in the case of 
a laceration. Diagnostic laparoscopy is not helpful in diagnosis of duodenal injury because of its retroperitoneal location [9, 10, 11, 12, 13]. AAST (American Association for the Surgery of Trauma) has classified duodenal injury into four grades. [Table 2] [4].

Prerequisite for duodenal trauma management is the mobilization of colon and Kocherisation of duodenum and ability to handle different surgical procedures based on complexity of injury.

The first task of management is the repair of duodenal laceration and prevention of leak. The duodenal decompression through tube duodenostomy, which can be done in three ways: (a) primary, where the tube is inserted directly in duodenum an orifice different from the wound; (b) anterograde, where the duodenum is decompressed by passing a tube through the pylorus towards the duodenum and (c) retrograde, where the tube is passed through the jejunum towards duodenum injury site.

In 1979 Stone and Fabian [14] introduced the use of the duodenostomy tube as "triple ostomy" (gastrostomy, duodenostomy and jejunostomy). They studied 237 patients and he found only 1 case of duodenal fistula when duodenostomy tube was applied. While 8 patients developed fistula when it was not used.

Another method of repair of duodenal injury is the use of mucosal or serosal patches, first introduced in 1960. Experimental models had proven that the apposition of serous membrane of mobilised jejunal loop to seal full-thickness, non-reconstructible duodenal injuries induced mucous coat in six to eight weeks [15, 16, 17].

In condition of duodenal injuries where entire duodenal circumference has been devitalised, a segmental resection and an end-to-end duodenal anastomosis can be perfomed. The resection of the first, third and fourth portions of the duodenum is not associated with a high risk of vascular involvement. The limiting step in the resection of the second portion is assigned to the arterial arcade shared with the pancreas. In this patient, we performed triple tube technique for two large traumatic duodenal perforations. This technique includes repair of duodenal perforation and prevent its leak by triple tube- gastrostomy, duodenostomy and jejunostomy. We performed retrograde duodenostomy, feeding jejunostomy and a gastrojejunostomy in place of gastrostomy. We expected the repair of two large perforations in a young male to progress into a stenosis of affected segment down flow obstruction. Gastrojejunostomy shall bypass the stomach contents and prevent this postoperative complication.

\section{CONCLUSION}

In a complex scenario as of duodenal perforation various modes of management have been advocated in literature, but none has been standardised. We have brought out successful management of multiple large perforations of duodenum following trauma that was managed with a modified triple tube decompression in which we substituted gastrostomy with a gastrojejunostomy.

\section{Conflicts of interests: None}

\section{REFERENCES}

[1]. Ivatury RR. Duodenal injuries: small but lethal lesions. Cirujano General 2003; 25(1):59-65.

[2]. Acosta]. M anagement of Specific Injuries, Injuries to the Duodenum. In: Townsend CM, Beauchamp RD, Evers BM, Mattox KL. Sabiston Textbook of Surgery, 18th ed. Philadelphia: Saunders-Elsevier; 2008. p. 505-6.

[3]. Carrillo EH, Richardson JD, Miller FB. Evolution in the management of duodenal injuries. J Trauma 1996;40:1037-6

[4]. Moore E E, Cogbill TH, Malangoni M D, Jurkovich $G$ J, Champion H R, Gennarelli T A, M cAninch J W, Pachter H L, Shackford SR, Trafton P G. Organ injury scaling, II: Pancreas, duodenum, small bowel, colon and rectum. J Trauma. (1990);30(11):1427-1429.

[5]. Lucas CE, Ledgerwood AM. Factors influencing outcome after blunt duodenal injury. J Trauma 1975;15:839-46

[6]. Olsen WR. The serum amylase in blunt abdominal trauma. J Trauma. 1973;13:201-4.

[7]. Huerta S, Bui T, Porral D, Lush S, Cinat M. Predictors of morbidity and mortality in patients with traumatic duodenal injuries. Am Surg 2005;71(9):763-7.

[8]. Jurkovich G], Bulger EM. Duodenum and pancreas. In: M oore EE, Feliciano DV, M attox KL, Eds. Trauma. 5th Ed., New York, M cGraw Hill, 2003, p:709-34.

[9]. Crippa S, Falconi M, Bettini R, et al. Isola-ted Blunt Duodenal Trauma: Delayed Diagnosis and Favorable Outcome with "Quadruple Tube" Decompression. JOP 2007;8(5):617-20. 
[10]. Brofman N, Atri M , Hanson JM , Grinblat L, Chughtai $T$, Brenneman F. Evaluation of bow el and mesenteric blunt trauma with multidetector CT. Radiographics 2006; 26(4):1119-31.

[11]. M iller LA, Shanmuganathan K. Multidetec-tor CT evaluation of abdominal trauma. Radiol Clin North Am 2005;43(6):1079-95.

[12]. Scaglione M, de Lutio di Castelguidone E, Scialpi M, M erola S, Diettrich Al, Lombardo P. Blunt trauma to the gastrointestinal tract and mesentery: is there a role for helical $\mathrm{CT}$ in the decision-making process? Eur J Radiol 2004;50(1):67-73.

[13].Brooks AJ, Boffard KD. Current techno-logy: laparoscopic surgey in Trauma. Trauma 1999; 1(1):53-60.

[14]. Stone HH, Fabian TC. Management of duodenal wounds. J Trauma. 1979;19:334-9.
[15]. Garcýáa-Nun ez LM, Nun ez-Cantu' O, CabelloPasini R, Delgado-Aramburo JL, Soto-Ortega LE, Rivera-Cruz JM , et al. Trauma duodenal complejo. Co'mo elegir la terapeu'tica. Rev Sanid Milit M ex. 2008;62:109-17.

[16].Kobbold EE, Thal AP. A simple method for the management of experimental wounds to the duodenum. Surg Gynecol Obstet. 1963;116:340-4.

[17]. De Shazo CV, Snyder WH, Daugherty CG, Crenshaw CA. Mucosal pedicle graft of the jejunum for large gastrointestinal defects. Am J Surg. 1972;124:6712.

\section{How to cite this article:}

Devendra K. Prajapati, Kapil Rampal, Mukesh Soni, Jyoti M Prajapati. Case Report on Two Large Duodenal Perforations and Their Management in Emergency Conditions. Int J Intg M ed Sci 2016;3(5):280-284. DOI: 10.16965/ ijims.2016.117 